\title{
A rollable ultra-light polymer electrolyte membrane fuel cell
}

\author{
Taehyun Park ${ }^{1,2,5}$, Yun Sik Kang ${ }^{2,5}$, Segeun Jang ${ }^{1,3,5}$, Suk Won Cha ${ }^{1}$, Mansoo Choi ${ }^{1,3}$ and Sung Jong Yoo ${ }^{2,4}$ \\ We have developed a highly flexible, ultra-light and thin polymer electrolyte membrane fuel cell that can be used as a portable \\ power source for flexible electronics. To achieve such flexibility and ultra-lightness, we fabricated a thin flow-field plate using \\ a thermal imprinting process and combined it with a laser-machined metal current collector. The air-breathing fuel cell, with \\ a thickness of $0.992 \mathrm{~mm}$ and a weight of $2.23 \mathrm{~g}$, demonstrated a total power of $508 \mathrm{~mW}$ and a performance degradation of \\ $<10 \%$ after severe bending fatigue (200 repeated bends). This high power per weight $\left(0.228 \mathrm{~W} \mathrm{~g}^{-1}\right)$ and robust bending \\ durability have never been observed before. The highly flexible architecture enabled the operation of the fuel cell in an S-shape \\ or even in a rolled-up state without any significant performance loss. We have fabricated a cylindrical planar stack of 10 fuel \\ cells and successfully carried out its outdoor operation to demonstrate its practical applications in various fields.
}

NPG Asia Materials (2017) 9, e384; doi:10.1038/am.2017.72; published online 26 May 2017

\section{INTRODUCTION}

The capability of fabricating small, flexible and lightweight power sources is key to cope with the increasing demand for current and future portable electronics. Flexible electronics are considered the next ubiquitous platform due to their potential applications in the military, wearable computers and smartphones, biomedical diagnostic devices, roll-up displays and electronic paper. ${ }^{1-10}$ Because portable electronics require not only state-of-the-art electronic engineering but also flexible and bendable power sources, extensive efforts have been made to meet such technological demands including flexible supercapacitors, secondary Li-ion batteries and fuel cells. ${ }^{11-15}$ While supercapacitors obtain high power density by sacrificing energy storage and secondary Li-ion batteries have reached their theoretical maximum energy density, fuel cell technology still has the potential to increase both power and energy density. ${ }^{16}$ Therefore, fuel cell technology could be the next-generation portable power source for the flexible electronics of the future.

In this regard, flexible fuel cell designs have been reported several times. Miniaturized flexible fuel cells with high power density based on micro-electro-mechanical systems technology have been proposed, but they have some practical limitations such as difficulty in scale-up and high manufacturing cost. ${ }^{17-21}$ Subsequent research has attempted to resolve such problems by using low-cost, facile processing techniques, including soft lithography employing commercially available polymers and electrically conductive materials. ${ }^{22-29}$ Although these reported materials have shown potential as portable power sources, the technology in such reports was not sufficient to be adopted in current and future flexible electronics due to thick and heavy device construction, low power output, stacking issues or high catalyst loading. In particular, bending-induced mechanical strain, which increases linearly with thickness, can damage the membraneelectrode assembly (MEA) and reduce the long-term durability of fuel cells. $^{22,29}$ Therefore, flexible fuel cells should have a geometry sufficiently thin to both avoid strain damage and maintain high structural degrees of freedom.

In this study, we report rollable ultra-light fuel cells (RUFCs) with two operation types: air-breathing (passive) and active. The air-breathing RUFC was composed of an anode flow-field plate, anode/cathode current collectors, gas diffusion layers (GDLs) and a catalyst-coated membrane with a total thickness of $0.992 \mathrm{~mm}$ and a weight of $2.23 \mathrm{~g}$. For the active RUFC, only one component, a cathode flow-field plate, was added to the air-breathing RUFC. By employing a thermal imprinting method with a thin polycarbonate (PC) film, we achieved well-defined flow-field plates with an effective distribution of reactants and high flexibility. In addition, with the aid of a facile laser-machining process with stainless steel sheets, a metal current collector with excellent gas permeability, electrical conductivity and low flexural rigidity was utilized in this work.

\footnotetext{
${ }^{1}$ Department of Mechanical and Aerospace Engineering, Seoul National University, Seoul, Republic of Korea; ${ }^{2}$ Fuel Cell Research Center, Korea Institute of Science and Technology (KIST), Seoul, Republic of Korea; ${ }^{3}$ Global Frontier Center for Multiscale Energy Systems, Seoul National University, Seoul, Republic of Korea and ${ }^{4}$ Clean Energy and Chemical Engineering, Korea University of Science and Technology, Daejeon, Republic of Korea

5These authors contributed equally to this work.

Correspondence: Professor SW Cha, Fuel Cell Research Center, Korea Institute of Science and Technology (KIST), 5, Hwarang-ro 14-gil, Seoul, Seongbuk-gu 02792, Republic of Korea. E-mail: swcha@snu.ac.kr

or Professor M Choi, Department of Mechanical and Aerospace Engineering, Seoul National University, Seoul, Shinlimdong 08826, Republic of Korea.

E-mail: mchoi@snu.ac.kr

or Dr SJ Yoo, Fuel Cell Research Center, Korea Institute of Science and Technology (KIST), 5, Hwarang-ro 14-gil, Seoul, Seongbuk-gu 02792, Republic of Korea.

E-mail: ysj@kist.re.kr

Received 13 December 2016; revised 8 March 2017; accepted 13 March 2017
} 
a

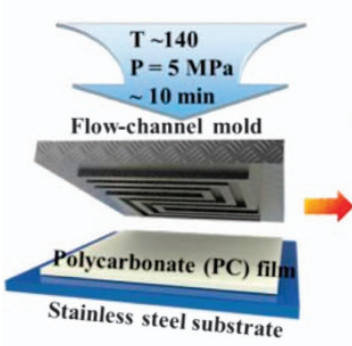

b

Flow-channel patterned PC film

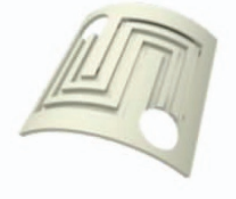

C

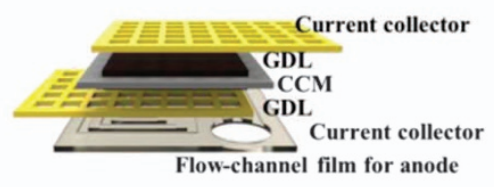

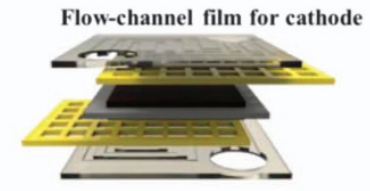

d Air-breathing type RUFC
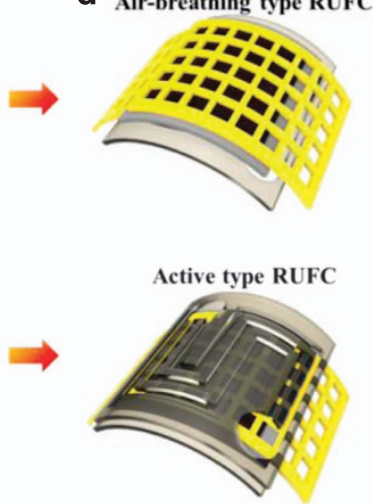

e

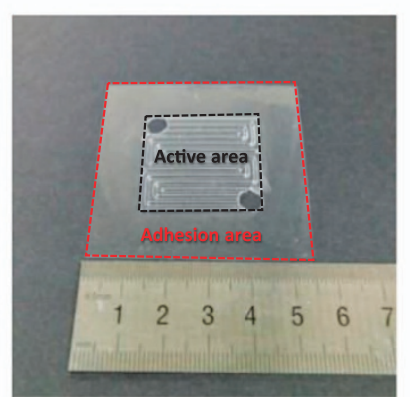

f

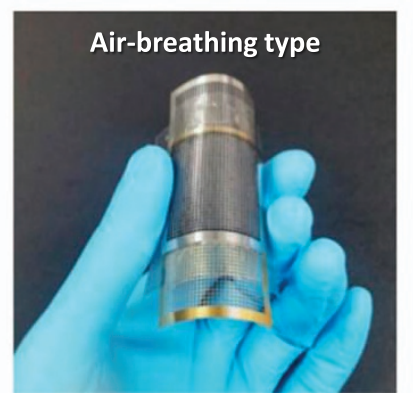

g

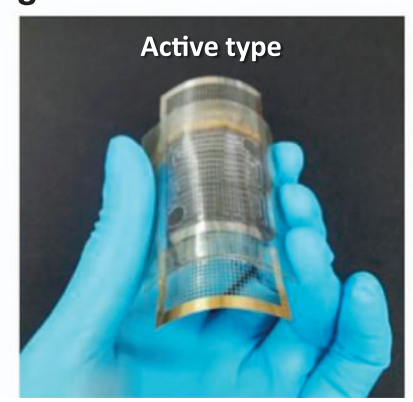

Figure 1 Schematic illustrations for the fabrication procedure of the RUFCs. (a) Fabrication of the flow-field thin plate through thermal imprinting with the PC film. (b) Flow-channel-patterned PC film. (c, d) Stacking and assembling the components of the air-breathing (upper) and active RUFCs (lower). Digital camera images of the (e) flow-channel-patterned PC film and the (f) completed air-breathing and (g) active RUFCs. CCM, catalyst-coated membrane; GDL, gas diffusion layer; RUFC, rollable ultra-light fuel cell.

\section{EXPERIMENTAL PROCEDURES}

\section{Fabrication of the flow-field thin film and metal grid current} collector

The flow-field thin film was prepared using a thermal imprinting process. First, we fabricated a flow-channel stainless steel mold using a computerized numerical control milling machine, with a channel depth, width, and height of $0.5,1$, and $1 \mathrm{~mm}$, respectively. A PC film $(200 \mu \mathrm{m}$ thick $)$ was placed on the flow-channel stainless steel mold and hot-pressed under hydrostatic pressure $(5 \mathrm{MPa})$ at $150^{\circ} \mathrm{C}$ for $10 \mathrm{~min}$. After lowering the temperature to $60^{\circ} \mathrm{C}$, the flow-channel-patterned thin film was removed from the stainless steel mold. To make the inlet and outlet of the gases, two holes were drilled at the ends of the flow channel. The metal grid was fabricated based on the laser cutting process of a thin stainless steel sheet $(50 \mu \mathrm{m}$ thick) with a square mesh size of $1 \times 1 \mathrm{~mm}$, and the $20 \mathrm{~nm}$ thick gold film was sputtered onto the metal grid using a commercial sputtering system (AT12, A-Tech System, Incheon, Republic of Korea). The pressure of the Ar gas, direct current (DC) sputtering power and target-to-substrate distance were $0.67 \mathrm{~Pa}, 100 \mathrm{~W}$ and $8 \mathrm{~cm}$, respectively.

MEA preparation and fabrication of the ultra-light rollable fuel cell The MEA was prepared using the following steps. First, a Nafion 212 membrane (DuPont, Wilmington, DE, USA) was employed as a protonconducting electrolyte without pretreatment and mounted on a suction-type hot plate while the temperature was maintained at $80^{\circ} \mathrm{C}$. The catalyst ink for the anode and cathode catalyst layers was prepared by mixing deionized water (18.2 M $\Omega \mathrm{cm}$, Millipore), $5 \mathrm{wt} \%$ Nafion solution (DuPont) and isopropyl alcohol (Sigma-Aldrich, St Louis, MO, USA) with $40 \mathrm{wt} \% \mathrm{Pt} / \mathrm{C}$ (Johnson Matthey, Royston, UK). The prepared catalyst ink was blended using a vortexer and ultrasonic treatment and then sprayed onto the anode and cathode sides of the mounted Nafion 212 membrane (DuPont). The Pt loading of the asfabricated catalyst-coated membrane was $0.45 \mathrm{mg} \mathrm{cm}^{-2}$ at each electrode, and the active geometric areas of the MEAs were set to $9.0 \mathrm{~cm}^{2}$. After this process, the catalyst-coated membrane was placed between two GDLs (carbon paper 10BC, SGL Carbon, Wiesbaden, Germany) and hot-pressed under hydrostatic pressure $(10 \mathrm{MPa})$ at $120^{\circ} \mathrm{C}$ for $10 \mathrm{~min}$. Finally, the ultra-light rollable fuel cell was assembled by stacking the flow-field thin film, gold-coated metal grid and homemade MEA using a thin adhesive sealant tape $(50 \mu \mathrm{m}$ thick, $3 \mathrm{M})$. This assembly was hot-pressed under hydrostatic pressure $(1 \mathrm{MPa})$ at $60^{\circ} \mathrm{C}$ for better adhesion of each component.

\section{Fabrication of the ultra-light rollable fuel cell stack}

The planar fuel cell stack was fabricated using 10 fuel cells, arranged with a two column $\times$ five row structure. The anode of one fuel cell was connected to another fuel cell to increase the total voltage via a series connection. This planar fuel cell stack was intentionally bent into a cylindrical shape. Dry $\mathrm{H}_{2}$ was supplied into the inside of a cylinder-like fuel cell stack. To demonstrate the fuel cell stack operating outside, an $\mathrm{H}_{2}$-storing metal hydride cartridge (Hydrostick, Horizon, Singapore) was used.

\section{Electrochemical characterization}

The as-fabricated fuel cell was mounted on a vise to bend it, and the performances were measured at two shapes: flat and bent with a radius of $2 \mathrm{~cm}$. The volumetric flow rates of $\mathrm{H}_{2}$ and air into the fuel cell were both $200 \mathrm{~cm}^{3}$ per min. Each gas was supplied with the relative humidity (RH) of $94 \%$ at $25^{\circ} \mathrm{C}$. The wet/dry cycle test was performed by switching the $\mathrm{RH}$ values of the $\mathrm{H}_{2}$ and air gases from 100 to $0 \%$, while open-circuit voltages (OCVs) and the power densities at $0.6 \mathrm{~V}$ vs reversible hydrogen electrode (RHE) of the active RUFC were recorded at the same time. Each wet or dry step was maintained for $10 \mathrm{~min}$, and the cycle was repeated six times. After completing the last cycle, the RUFC was operated with dry gases for $20 \mathrm{~min}$ to examine the feasibility of dry operation. The air-breathing RUFC was operated under atmospheric conditions ( $\mathrm{RH}$ of $30 \%$ at $25^{\circ} \mathrm{C}$ ). The single cell performance and the corresponding electrochemical impedance spectra (EIS) were measured using a Solartron 1260/1287 (Solartron Analytical, Hampshire, UK). 
a

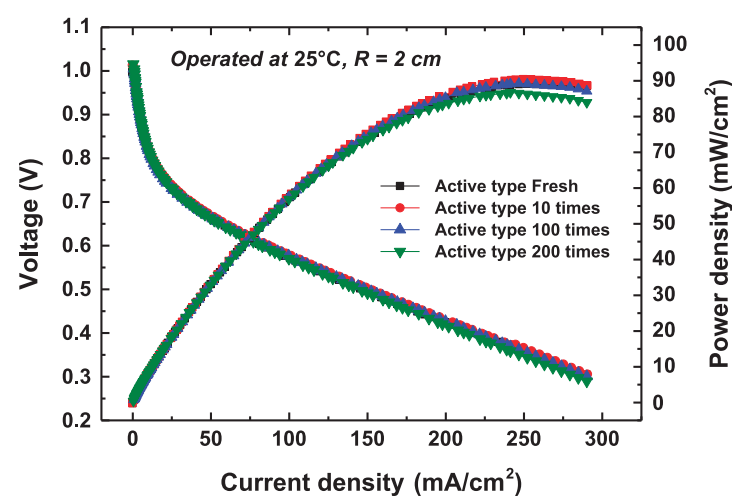

C

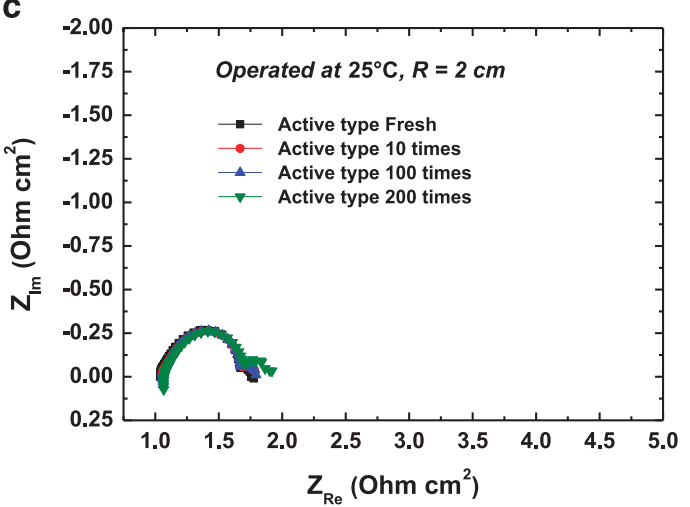

e

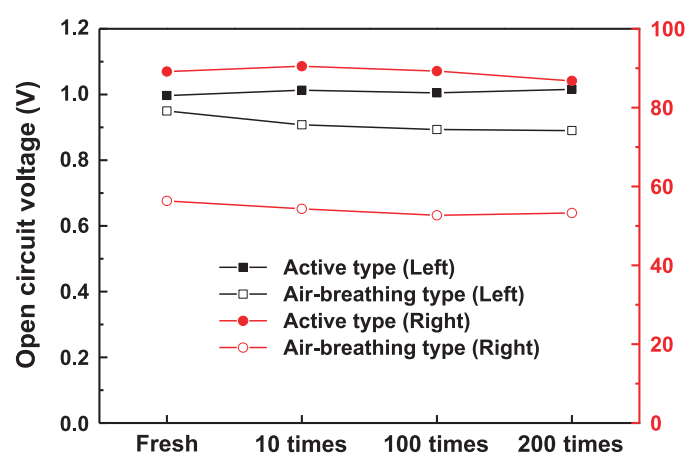

b

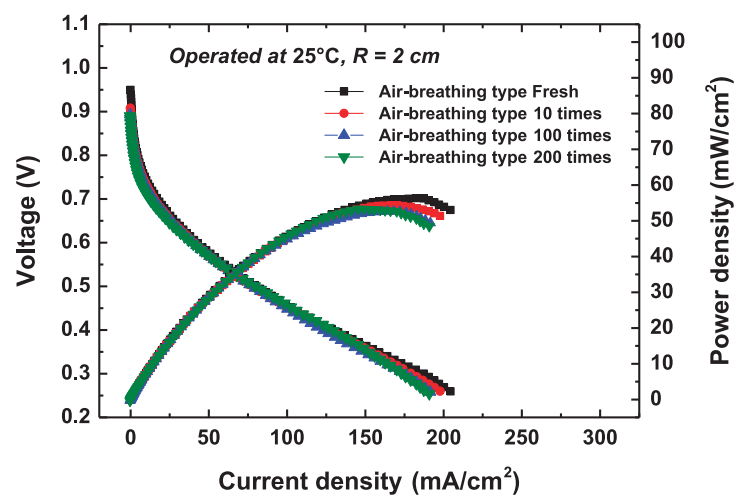

d

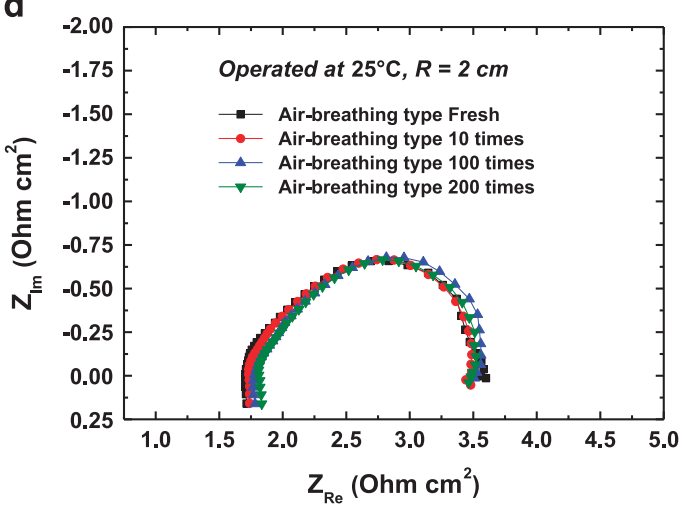

f

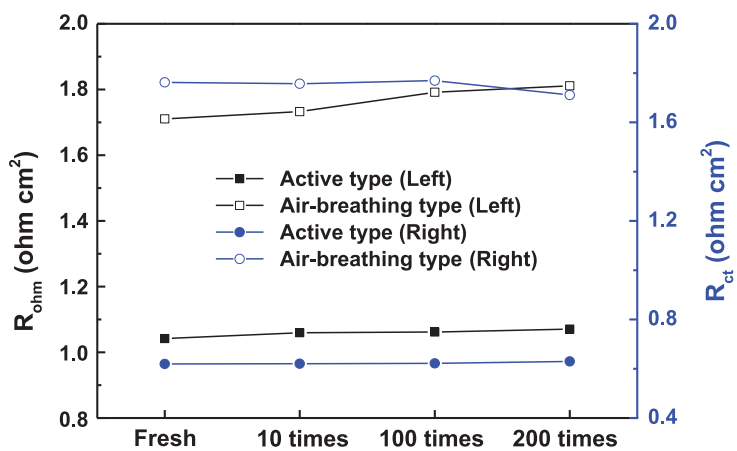

Figure 2 Polarization curves for the (a) active and (b) air-breathing RUFCs before and after the repeated bending test and the corresponding electrochemical impedance spectra at $0.5 \mathrm{~V}$ vs RHE (c, d). Comparison of open-circuit voltages and maximum power densities of the (e) active and (f) air-breathing RUFCs before and after the repeated bending test. RUFC, rollable ultra-light fuel cell.

Before measuring the performance, the cell was activated by measuring the polarization curves repeatedly from an $\mathrm{OCV}$ to $0.25 \mathrm{~V}$ in potentiodynamic mode with a voltaic sweep rate of $15 \mathrm{mV}$ per s. Immediately after measuring the polarization curve, the corresponding EIS data at $0.5 \mathrm{~V}$ vs RHE were measured by applying a sinusoidal input with an amplitude of $30 \mathrm{mV}$ to monitor the current response. The frequency range was $10^{5}-10^{-1} \mathrm{~Hz}$, from high to low frequency. The RUFC was then repeatedly bent 10,100 and 200 times, with a bending radius of $1 \mathrm{~cm}$ in this deliberate bending process. The RUFC was then characterized again after the repeated bending by following the same process as above.

The long-term durability of the active RUFC was also evaluated. During the long-term operation, polarization curves were measured repetitively from OCV to $0.25 \mathrm{~V}$ in potentiodynamic mode with a sweep rate of $15 \mathrm{mV}$ per s. Fully humidified $\mathrm{H}_{2}$ and air gases were supplied to the anode and cathode of the active RUFC, respectively, and the test was repeated for $120 \mathrm{~h}$. After $120 \mathrm{~h}$ of continuous operation, OCVs and maximum power densities of the active RUFC were examined.

\section{RESULTS AND DISCUSSION}

Figure 1a-d show the two-step fabrication procedure of these RUFCs: (a) fabrication of the flow-field thin plate through thermal imprinting with PC films and (b) stacking and assembling the components of the RUFCs. For the air-breathing RUFC, an anode flow-field thin plate, anode/cathode metal grid current collectors and a custom-built MEA were used. For the active RUFC, a cathode flow-field plate was added to the air-breathing RUFC to control the air flow to the fuel cell (see 'Experimental Procedures' for more details). Figure 1e-g show digital camera images of the fabricated products after each step. The flow-channel-patterned $(3 \times 3 \mathrm{~cm})$ PC film (thickness of $200 \mu \mathrm{m}$ ) showed high structural pattern fidelity due to the use of a thermal imprinting method. The total RUFC size was set to $5.5 \times 5.5 \mathrm{~cm}$ for robust assembly and to minimize the gas crossover by securing sufficient adhesive area (Figure 1e). This transparent, large-scale and 
a

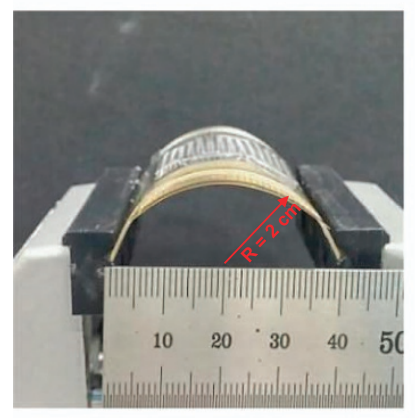

b

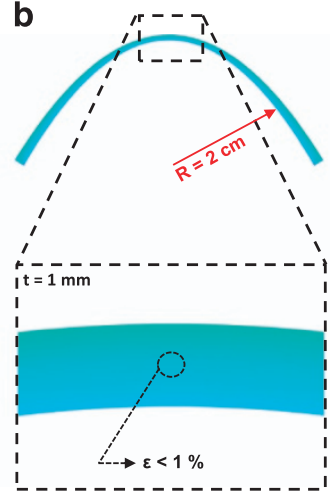

C

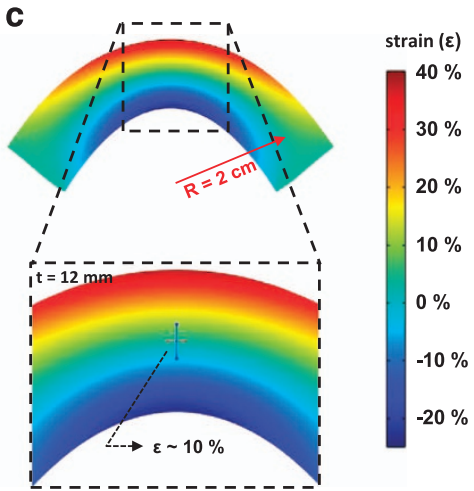

Figure 3 (a) Digital camera image of the active RUFC as it is bent. (b, c) Internal strain calculation results of 1 mm thick PC and 12 mm thick PDMS-based flexible fuel cells. PC, polycarbonate; RUFC, rollable ultra-light fuel cell.

thin patterned PC film served as a flow-field plate to enable the fabrication of fuel cells with high flexibility, superior power per weight and low-cost production (Figure 1e). A layer of current collectors with a thin stainless steel grid (line width $100 \mu \mathrm{m}$, mesh size $1 \times 1 \mathrm{~mm}$ and total thickness $50 \mu \mathrm{m}$ ) provides good flexibility and high gas diffusibility. Furthermore, a coating of gold onto one side of the stainless steel grid ( $20 \mathrm{~nm}$ thick) provides better electrical contact between the GDL and the current collector. Our RUFC systems could not utilize the external pressure from the endplate clamping typical in conventional fuel cells; ${ }^{30}$ and therefore, we hot-pressed a catalystcoated membrane between two GDLs to avoid dislocation during bending and rolling. Furthermore, this hot-pressing procedure reduces the internal resistance and overall thickness of the MEA. ${ }^{31}$ The completed air-breathing and active RUFCs showed good device integrity for flexible portable usage (Figure if and g). Additional details about the fabrication of these devices can be found in 'Experimental Procedures'.

Figure $2 \mathrm{a}-\mathrm{d}$ show the polarization curves and corresponding EIS. The initial OCVs of the active and air-breathing RUFCs were 1.00 and $0.960 \mathrm{~V}$, respectively, which are close to the theoretical voltage of a $\mathrm{H}_{2}$-air fuel cell. Therefore, the anode and cathode of the RUFCs were fully polarized by $\mathrm{H}_{2}$ and air, and the gas barrier was sealed well. ${ }^{32,33}$ The stoichiometry numbers of $\mathrm{H}_{2}$ and air were 11.5 and 4.8 in the anode and cathode, respectively, as the RUFC operates at $2.5 \mathrm{~A}$ (the maximum current measured). The reason for such high stoichiometry numbers is to evaluate the maximal performance of the newly devised fuel cell. The active RUFC exhibited higher performance than the air-breathing cell, with maximum power densities of 89.2 (total $803 \mathrm{~mW}$ ) and $56.4 \mathrm{~mW} \mathrm{~cm}^{-2}$ (total $508 \mathrm{~mW}$ ), respectively, when bent with a radius of $2 \mathrm{~cm}$ (Figure $2 \mathrm{a}$ and $\mathrm{b}$ ). These values are because the supply of air in the active RUFC is abundant because of forced convection, resulting in enhanced $\mathrm{H}_{2}$ and $\mathrm{O}_{2}$ diffusion into each GDL, which cannot be expected for the natural convection in the air-breathing RUFC, as observed previously. ${ }^{34,35}$

Durability against repeated bending is one of the crucial factors in all flexible electronics. Therefore, we performed repeated bending tests to examine their fatigue durability. Four cases $(0,10,100$ and 200 bending cycles) were set up, and the electrochemical characteristics for each case were investigated. The performances of both the active and air-breathing RUFCs did not decrease significantly with repeated bending (Figure $2 \mathrm{a}$ and $\mathrm{b}$ ). Even after 200 bending cycles, the maximum power densities in both the active and air-breathing RUFCs decreased by $<10 \%$. Although the cumulative bending cycles seem to slightly lower the OCV $(0.960-0.890 \mathrm{~V})$ of the air-breathing RUFC, it is supposed that such decrease would have occurred from the deteriorative sealing state by bending fatigue. However, the variation of the performance reveals that such decrease in the OCV is not a dominant factor in the performance of the RUFC. Both the active and air-breathing RUFCs have shown high OCVs over $0.9 \mathrm{~V}$, which proves that our RUFCs are well designed and that there were no sealing or packaging problems during their operation. ${ }^{32}$ In addition, the results of a repetitive wet/dry test further prove the superiority on sealing and packaging robustness, with high OCV values over $0.95 \mathrm{~V}$ indicating that crack formation and gas leakage had not occurred during the test (Supplementary Figure S1). The power density at $0.6 \mathrm{~V}$ vs RHE of the active RUFC in wet conditions ( $\mathrm{RH} 100 \%$ of air and $\mathrm{H}_{2}$ gases) is much higher than that in dry conditions ( $\mathrm{RH} 0 \%$ of air and $\mathrm{H}_{2}$ ), and this difference was maintained throughout the repeated wet/dry tests. The RUFC even operates without any significant performance loss under continuous dry conditions immediately after the wet/dry test for $110 \mathrm{~min}$ (Supplementary Figure S1). This result indicates that the other components operate without any problems. To the best of our knowledge, only one repeated bending test of flexible fuel cells has been reported in previous literature, ${ }^{22}$ where the performance of that fuel cell decreased continuously with bending for $>120$ times. Consequently, the as-fabricated RUFCs in this study are structurally robust and thus can endure the external force generated when used as flexible electronics, especially when compared to previous flexible fuel cells. In addition to bending, electrochemical durability was also tested (Supplementary Figure S2, Supplementary Table S1). It was observed that even after $120 \mathrm{~h}$ of continuous operation, the OCVs of the active RUFC remained very high (over $0.96 \mathrm{~V}$ ), which indicates that both electrodes of the active RUFC were well polarized and that there were no leakage or packaging problems. In addition, the maximum power densities of the active RUFC were also maintained for $96 \mathrm{~h}$ of operation and decreased by only $14 \%$ after $120 \mathrm{~h}$ compared to those of a conventional polymer electrolyte membrane fuel cell, which demonstrates the high long-term durability of our RUFCs. There was no significant performance loss by flooding due to two factors: the serpentine channel pattern and the contact angle of the PC (See Supplementary Figures S3 and S4, and additional discussion in Supplementary Information).

To quantitatively investigate the effect of repeated bending, the EIS at $0.5 \mathrm{~V}$ vs RHE was measured (Figure $2 \mathrm{c}$ and $\mathrm{d}$ ). The ohmic resistance $\left(R_{\mathrm{ohm}}\right)$ is theoretically generated from the ionic transport resistance (Nafion membrane (DuPont) and ionomer in the catalyst layer) and the external electrical resistance (bulk electrical 
a

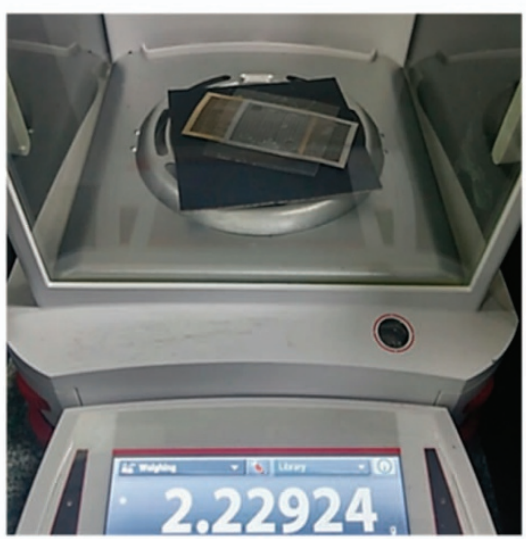

C

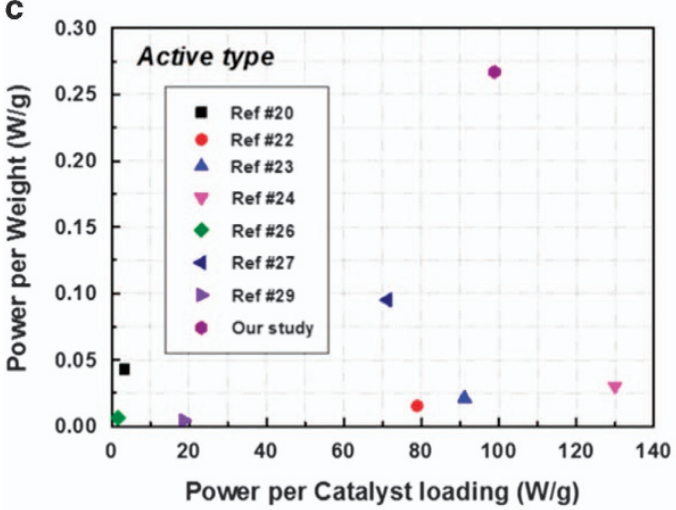

e

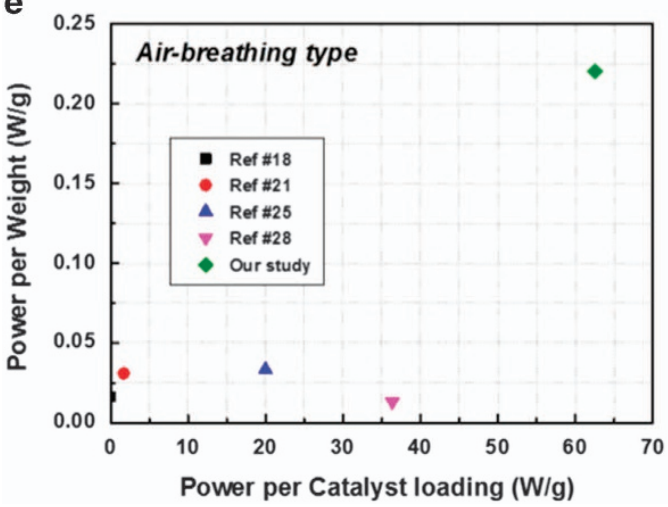

b

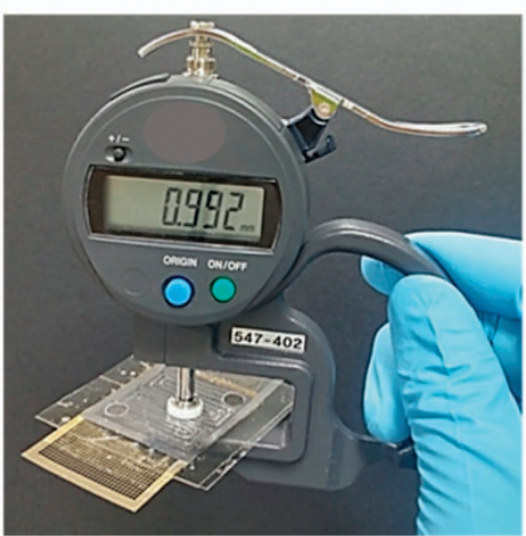

d

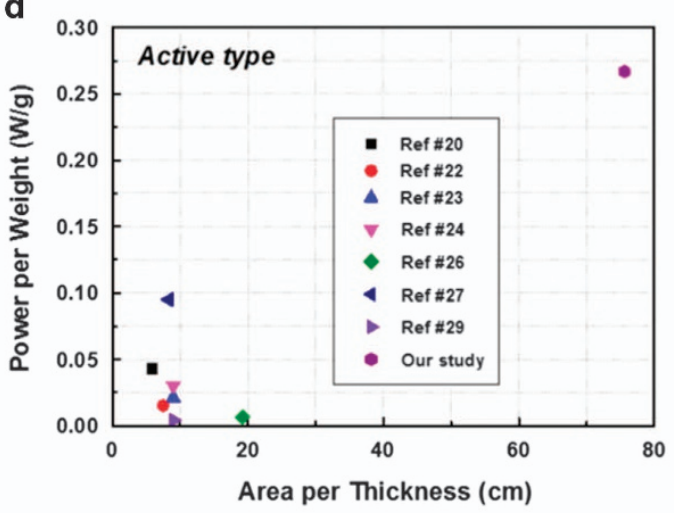

f

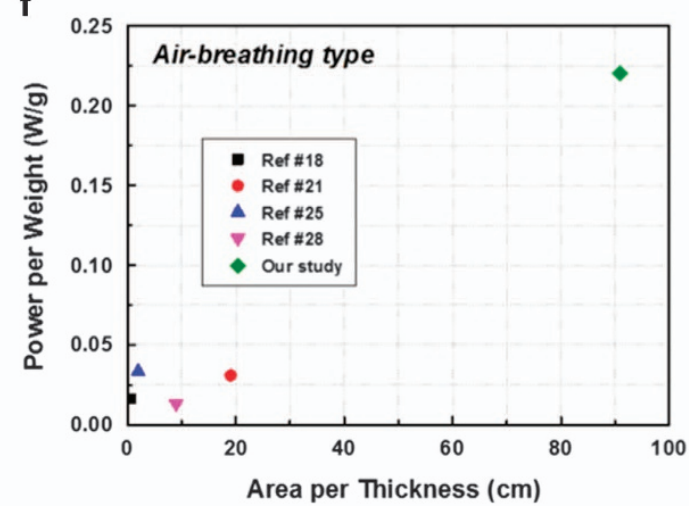

Figure 4 Digital camera images of (a) the weight and (b) thickness of the air-breathing RUFC. Comparison of RUFCs with other flexible fuel cells from other studies in terms of power per weight, power per catalyst loading and area per thickness. (c, d) for the active and (e, f) for the air-breathing RUFCs. RUFC, rollable ultra-light fuel cell.

resistance of materials and contact resistances between them), which is indicated by the intercept of the semicircle on the EIS with the real axis in the high frequency range. The charge transfer resistance $\left(R_{\mathrm{ct}}\right)$ is also calculated using the diameter of the semicircle at the middle and low-frequency ranges, which is caused mainly by electrochemical resistance from the cathode reaction. ${ }^{36,37}$ These spectra clearly visualize why the performance of the active RUFC is higher than that of the air-breathing one. Both the $R_{\mathrm{ohm}}$ and $R_{\mathrm{ct}}$ of the active RUFC are lower than those of the air-breathing one. The lower $R_{\mathrm{ohm}}$ of the active RUFC compared to the air-breathing one arises from the structural integrity due to the presence of the cathode flow-field plate. If the active RUFC is bent, it will generate higher compressive stress onto the MEA than the air-breathing one and will decrease the contact resistance at all componential interfaces. Such phenomena can be found in other studies. ${ }^{22,23}$ The lower $R_{\mathrm{ct}}$ of the active RUFC accounts for the better air supply by forced convection in the active RUFC than the natural convection of air in the air-breathing RUFC. ${ }^{34,35}$ In addition, the lower RH in the air-breathing RUFC by directly exposing the GDL to ambient air could be another cause of the higher $R_{\mathrm{ohm}}$ and $R_{\mathrm{ct}}$ values. When comparing the values of $R_{\mathrm{ohm}}$ and $R_{\mathrm{ct}}$ before and after the bending test, the $R_{\mathrm{ohm}}$ and $R_{\mathrm{ct}}$ values of both RUFCs were found to change by only a small amount, in accordance with the performance changes discussed above (Figure $2 \mathrm{e}$ and $\mathrm{f}$ ). A bending-induced mechanical strain has been 

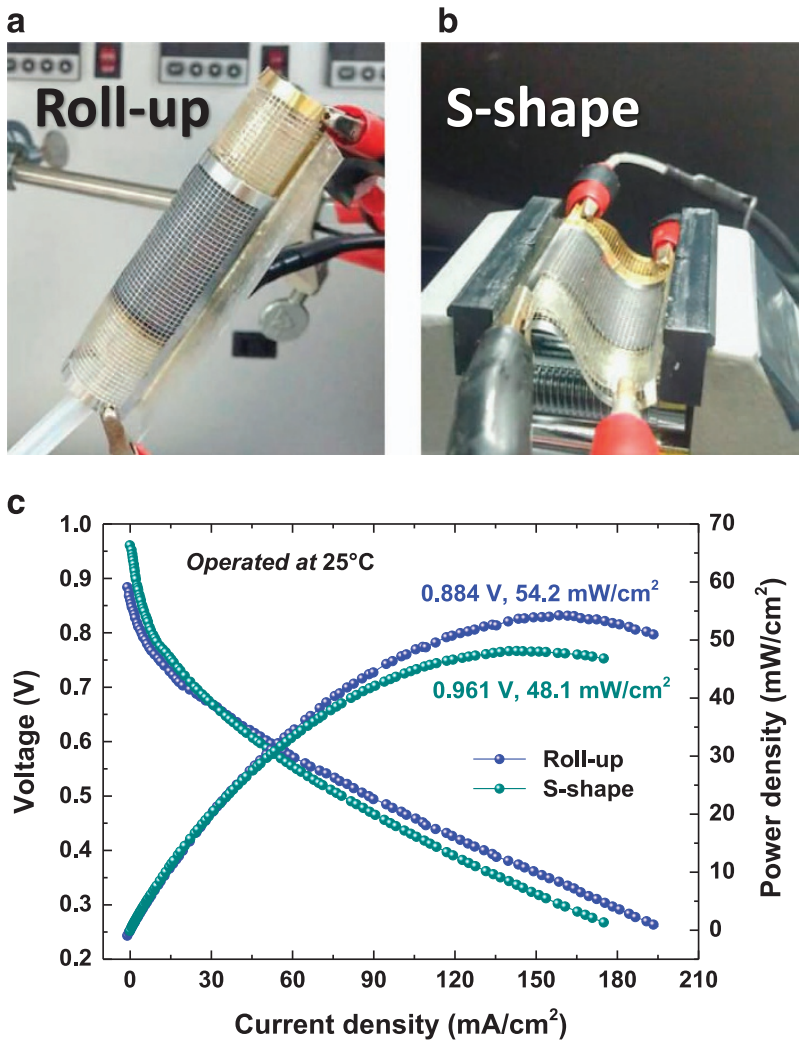

Figure 5 Digital camera images of RUFCs with various shapes. (a) Roll-up and (b) S-shape. (c) Polarization curves of roll-up and S-shape RUFCs. RUFC, rollable ultra-light fuel cell.

reported to damage and degrade the MEA. ${ }^{22,29}$ Considering that the strain is proportional to the overall thickness, the bending durability of the RUFCs arises from their extremely thin design and strong metal grid current collectors with low flexural rigidity. Because the thicknesses of the flexible fuel cells in previous studies were $12 \mathrm{~mm}$, more strain would be generated, and the bending durability was thus not of high quality. ${ }^{22}$

To compare the internal strain distribution of the RUFCs with those of previously reported flexible fuel cells, the lateral strain distributions of thick and thin fuel cells were calculated using COMSOL finite element analysis (Figure 3). The strain of the RUFC at the center line where the MEA is located is clearly small $(<1 \%)$, while that of the thick fuel cell is relatively high $(\sim 10 \%)$. When thick elastic materials (for example, polydimethylsiloxane (PDMS)) are employed in flow-field plates to achieve high flexibility and conformability, bending-induced lateral strain is thought to be inevitable because of their lower Young's modulus and thickness. In contrast, when flexible fuel cells are fabricated on thin and tough plastic films (for example, PC films as utilized in this study), lateral strains induced by bending could be effectively suppressed by the ultra-thin structure and relatively high Young's modulus. Similar phenomena regarding the thicknesses, Young's moduli and resulting performance in flexible electronics have been reported elsewhere. ${ }^{38,39}$ The detailed simulation process and further discussion of the structural advantages of the RUFC are explained with Supplementary Figure S5 in the Supplementary Information.

Figure $4 \mathrm{a}$ and $\mathrm{b}$ show digital camera images demonstrating the weight and thickness of the free standing air-breathing RUFC.
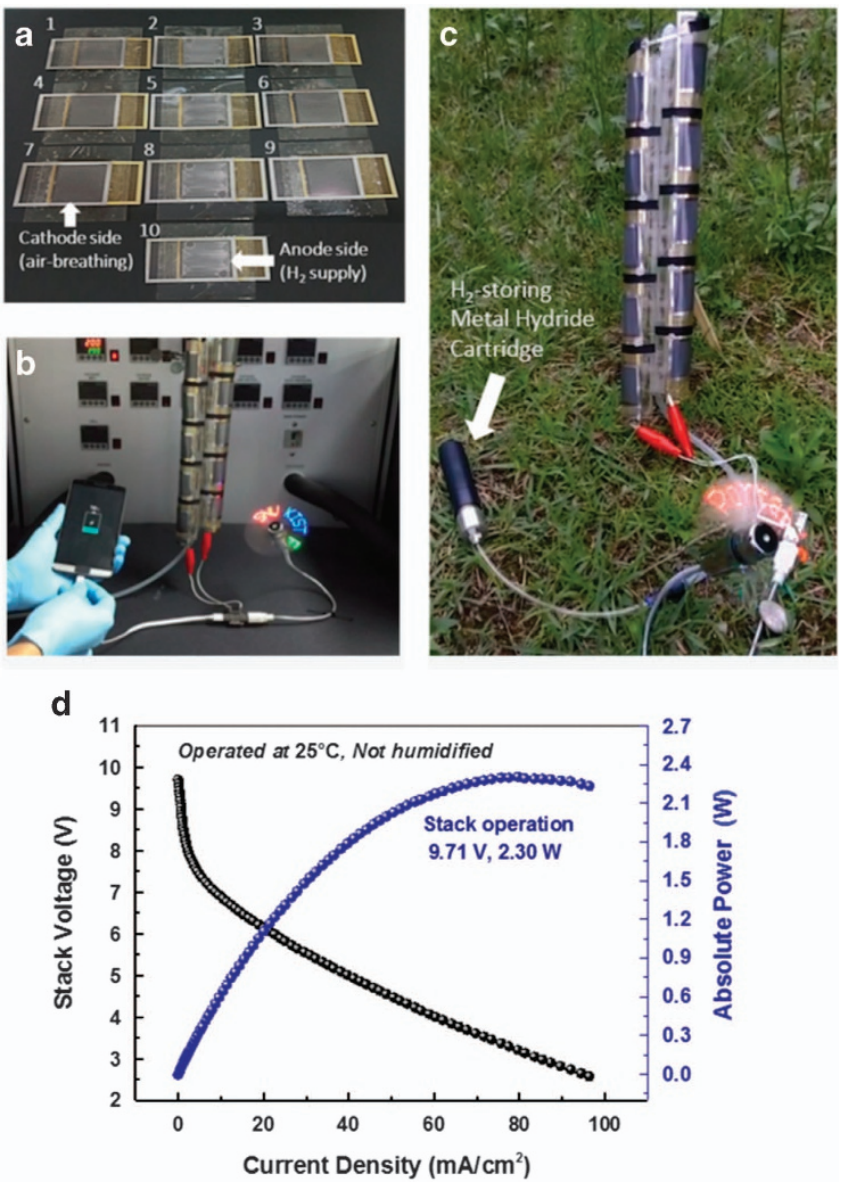

Figure 6 Digital camera images of (a) a portable stack of the 10 air-breathing RUFCs, (b) the demonstration of charging a smartphone and operating an electric LED fan with the stack and (c) outdoor operation of an electric LED fan with the stack and $\mathrm{H}_{2}$-storing metal hydride cartridge. (d) The polarization curve of the stack. RUFC, rollable ultra-light fuel cell.

The total weight and thickness are $\sim 2.23 \mathrm{~g}$ and $<1 \mathrm{~mm}$, respectively, confirming that our RUFC is lightweight and ultra thin. The performance of the active and air-breathing RUFCs in terms of their power per weight and power per catalyst loading is also compared with previous reports on flexible fuel cells (Figure $4 \mathrm{c}$ and $\mathrm{d}$ ). The active and air-breathing RUFCs show $>2.5$ - and 5-fold increases in power per weight, respectively, compared to the previously reported flexible fuel cells. To compare the ability to 'scale-up' these RUFCs with previously reported results (Figure $4 \mathrm{e}$ and f), we introduce here a new volumetric performance factor, 'area divided by thickness.' The performance of the RUFCs clearly achieved not only the highest power per weight, but also superior volumetric effectiveness for both the active and air-breathing flexible fuel cells. ${ }^{17-29}$

Because of its extremely thin and highly flexible design, the RUFC can be easily deformed to any desired shape. True to its name, 'rollable,' the RUFC can be rolled up (Figure 5a) or distorted into an S-shape (Figure $5 \mathrm{~b}$ ) without significantly affecting its performance compared to the undistorted values (that is, maximum power densities of 54.2 and $48.1 \mathrm{~mW} \mathrm{~cm}^{-2}$ for the rolled-up and S-shape, respectively, Figure 5c). This high degree of structural freedom allows applications in various environments such as epithermal, wearable or structurally complicated devices. 
Furthermore, we created a portable stack of 10 air-breathing RUFCs (Figure 6a). The shape of the fuel cell stack was intentionally designed to be circular to demonstrate its structural feasibility. The stacked device charged a smartphone and operated an electric LED fan simultaneously, successfully demonstrating its practical feasibility (Figure 6b,Supplementary Movie Clip available online). This fuel cell stack was made even more portable by using a metal hydride cartridge to store $\mathrm{H}_{2}$. This portable stack system also successfully operated an electric LED fan outside (Figure 6c) with a measured OCV of $9.71 \mathrm{~V}$ and maximum power of $2.30 \mathrm{~W}$ (Figure 6d) when operated at room temperature $\left(25^{\circ} \mathrm{C}\right)$ with $\mathrm{H}_{2}$ and ambient air. This power is lower than the value calculated from the maximum power density of $56.4 \mathrm{~mW} \mathrm{~cm}^{-2}$ in Figure $2 \mathrm{~b}$ because the modularization was not optimized for the prevention of current leakage or the inhomogeneous distribution of $\mathrm{H}_{2}$, and highly dry $\mathrm{H}_{2}$ (stored in a metal hydride cartridge) was used. ${ }^{40}$ Still, a power level usable for the operation of practical electronics gives us further insight into a new type of portable and flexible power sources.

\section{CONCLUSIONS}

We have demonstrated the fabrication and practical application of RUFCs for flexible electronics. Using well-defined thin flow-field plates, highly conductive and gas-permeable current collectors, and custom, hot-pressed MEA, we successfully constructed ultra-light and thin fuel cell devices. The as-fabricated RUFCs exhibited the highest power-per-weight values among previously reported flexible fuel cells and stable operation even in various deformed shapes such as rolled-up and S-shaped geometries. In addition, a portable, flexible planar stack composed of 10 air-breathing RUFCs was manufactured and utilized as a power source for charging and operating conventional electronic devices. With this novel approach, our RUFCs not only are potential next-generation portable power sources, but also suggest new designs for materials and systems for future flexible electronics.

\section{CONFLICT OF INTEREST}

The authors declare no conflict of interest.

\section{ACKNOWLEDGEMENTS}

This work was supported by the Global Frontier R\&D Program of the Center for Multiscale Energy System funded by the National Research Foundation under the Ministry of Science, ICT \& Future Planning, Korea (2016M3A6A7945505) and an NRF grant funded by MSIP (2017R1A2B2003363). This work is also supported financially by the New and Renewable Energy Core Technology of KETEP grant funded by MOTIE (20143030031340).

1 Boland, J. J. Flexible electronics: within touch of artificial skin. Nat. Mater. 9, 790-792 (2010).

2 Nathan, A., Ahnood, A., Cole, M. T., Lee, S., Suzuki, Y., Hiralal, P., Bonaccorso, F., Hasan, T., Garcia-Gancedo, L., Dyadyusha, A., Haque, S., Andrew, P., Hofmann, S., Moultrie, J., Chu, D., Flewitt, A. J., Ferrari, A. C., Kelly, M. J., Robertson, J., Amaratunga, G. A. J. \& Milne, W. I. Flexible electronics: the next ubiquitous platform. Proc. IEEE 100, 1486-1517 (2012).

3 Huang, S., Wu, H., Zhou, M., Zhao, C., Yu, Z., Ruan, Z. \& Pan, W. A flexible and transparent ceramic nanobelt network for soft electronics. NPG Asia Mater. 6 e86 (2014).

4 Kim, D.-H., Ghaffari, R., Lu, N. \& Rogers, J. A. Flexible and stretchable electronics for biointegrated devices. Annu. Rev. Biomed. Eng. 14, 113-128 (2012).

5 Gutruf, P., Shah, C. C. M., Walia, S., Nili, H., Zoolfakar, A. S., Karnutsch, C., Kalantar-zadeh, K., Sriram, S. \& Bhaskaran, M. Transparent functional oxide stretchable electronics: micro-tectonics enabled high strain electrodes. NPG Asia Mater. 5, e62-e67 (2013).
6 Kim, D.-H., Lu, N., Ghaffari, R. \& Rogers, J. A. Inorganic semiconductor nanomaterials for flexible and stretchable bio-integrated electronics. NPG Asia Mater. 4, e15 (2012).

7 Yu, C., Li, Y., Zhang, X., Huang, X., Malyarchuk, V., Wang, S., Shi, Y., Gao, L., Su, Y. Zhang, Y., Xu, H., Hanlon, R. T., Huang, Y. \& Rogers, J. A. Adaptive optoelectronic camouflage systems with designs inspired by cephalopod skins. Proc. Natl Acad. Sci. USA 111, 12998-13003 (2014).

8 Sekitani, T., Nakajima, H., Maeda, H., Fukushima, T., Aida, T., Hata, K. \& Someya, T. Stretchable active-matrix organic light-emitting diode display using printable elastic conductors. Nat. Mater. 8, 494-499 (2009).

9 Rogers, J. A., Someya, T. \& Huang, Y. Materials and mechanics for stretchable electronics. Science 327, 1603-1607 (2010).

10 Kaltenbrunner, M., Sekitani, T., Reeder, J., Yokota, T., Kuribara, K., Tokuhara, T., Drack, M., Schwödiauer, R., Graz, I., Bauer-Gogonea, S., Bauer, S. \& Someya, T. An ultra-lightweight design for imperceptible plastic electronics. Nature 499, 458-463 (2013).

11 Li, R., Wang, Y., Zhou, C., Wang, C., Ba, X., Li, Y., Huang, X. \& Liu, J. Carbon-stabilized high-capacity ferroferric oxide nanorod array for flexible solid-state alkaline battery-supercapacitor hybrid device with high environmental suitability. Adv. Funct. Mater. 25, 5384-5394 (2015).

12 El-Kady, M. F., Strong, V., Dubin, S. \& Kaner, R. B. Laser scribing of high-performance and flexible graphene-based electrochemical capacitors. Science 335, 1326-1330 (2012).

13 Oyaizu, K. \& Nishide, H. Toward flexible batteries. Science 319, 737-738 (2008).

14 Gaikwad, A. M., Khau, B. V., Davies, G., Hertzberg, B., Steingart, D. A. \& Arias, A. C. A high areal capacity flexible lithium-ion battery with a strain-compliant design. Adv. Energy Mater. 5, 1401389 (2015).

15 El-Kady, M. F. \& Kaner, R. B. Scalable fabrication of high-power graphene micro-supercapacitors for flexible and on-chip energy storage. Nat. Commun. 4, 1475 (2013).

16 Winter, M. \& Brodd, R. J. What are batteries, fuel cells, and supercapacitors? Chem. Rev. 104, 4245-4269 (2004).

17 Hahn, R., Wagner, S., Schmitz, A. \& Reichl, H. Development of a planar micro fuel cell with thin film and micro patterning technologies. J. Power Sources 131, 73-78 (2004).

18 Tominaka, S., Nishizeko, H., Ohta, S. \& Osaka, T. On-chip fuel cells for safe and high-power operation: investigation of alcohol fuel solutions. Energy Environ. Sci. 2, 849-852 (2009).

19 Tominaka, S., Nishizeko, H., Mizuno, J. \& Osaka, T. Bendable fuel cells: on-chip fuel cell on a flexible polymer substrate. Energy Environ. Sci. 2, 1074-1077 (2009).

20 Weinmueller, C., Tautschnig, G., Hotz, N. \& Poulikakos, D. A flexible direct methanol micro-fuel cell based on a metalized, photosensitive polymer film. J. Power Sources 195, 3849-3857 (2010).

21 Wu, Z., Wang, X., Kuang, X. \& Liu, L. A flexible, foldable, tubular $\mu$ DMFC for powering wrist bands. IEEE 29th International Conference Micro Electro Mechanical Systems 43-46 (2016)

22 Chang, I., Park, T., Lee, J., Lee, M. H., Ko, S. H. \& Cha, S. W. Bendable polymer electrolyte fuel cell using highly flexible $\mathrm{Ag}$ nanowire percolation network current collectors. J. Mater. Chem. A 1, 8541-8546 (2013).

23 Chang, I., Park, T., Lee, J., Lee, H. B., Ji, S., Lee, M. H., Ko, S. H. \& Cha, S. W. Performance enhancement in bendable fuel cell using highly conductive Ag nanowires. Int. J. Hydrogen Energy 39, 7422-7427 (2014).

24 Chang, I., Park, T., Lee, J., Lee, H. B., Ko, S. H. \& Cha, S. W. Flexible fuel cell using stiffness-controlled endplate. Int. J. Hydrogen Energy 41, 6013-6019 (2016).

25 Hsu, F.-K., Lee, M.-S., Lin, C.-C., Lin, Y.-K. \& Hsu, W.-T. A flexible portable proton exchange membrane fuel cell. J. Power Sources 219, 180-187 (2012).

26 Hollinger, A. S. \& Kenis, P. J. A. Manufacturing all-polymer laminar flow-based fuel cells. J. Power Sources 240, 486-493 (2013).

27 Wheldon, J., Lee, W.-J., Lim, D.-H., Broste, A. B., Bollinger, M. \& Smyrl, W. H. High-performance flexible miniature fuel cell. Electrochem. Solid-State Lett. 12, B86-B89 (2009).

28 Chang, I., Lee, M. H., Lee, J. H., Kim, Y. S. \& Cha, S. W. Air-breathing flexible polydimethylsiloxane (PDMS)-based fuel cell. Int. J. Precis. Eng. Man. 14, 501-504 (2013).

29 Park, T., Chang, I., Lee, J., Ko, S. H. \& Cha, S. W. Performance variation of flexible polymer electrolyte fuel cell with Ag nanowire current collector under torsion. ECS Trans. 64, 927-934 (2014).

30 Kim, O.-H., Cho, Y.-H., Kang, S. H., Park, H.-Y., Kim, M., Lim, J. W., Chung, D. Y., Lee, M. J., Choe, H. \& Sung, Y.-E. Ordered macroporous platinum electrode and enhanced mass transfer in fuel cells using inverse opal structure. Nat. Commun. 4 , 2473 (2013).

31 Lai, C., Lin, J., Hsueh, K., Hwang, C., Tsay, K., Tsai, L. \& Peng, Y. On the electrochemical impedance spectroscopy of direct methanol fuel cell. Int. J. Hydrogen Energy 32, 4381-4388 (2007).

32 O'Hayre, R., Cha, S.-W., Colella, W. \& Prinz, F. B. Fuel Cell Fundamentals, John Wiley \& Sons, (2009).

33 Barbir, F. Pem Fuel Cells: Theory and Practice 2nd edn (Elsevier, 2012).

34 Fabian, T., Posner, J. D., O'Hayre, R., Cha, S. W., Eaton, J. K., Prinz, F. B. \& Santiago, J. G. The role of ambient conditions on the performance of a planar, air-breathing hydrogen PEM fuel cell. J. Power Sources 161, 168-182 (2006).

35 O'Hayre, R., Fabian, T., Litster, S., Prinz, F. B. \& Santiago, J. G. Engineering model of a passive planar air breathing fuel cell cathode. J. Power Sources 167, 118-129 (2007).

36 Yuan, X., Wang, H., Colin Sun, J. \& Zhang, J. AC impedance technique in PEM fuel cell diagnosis-a review. Int. J. Hydrogen Energy 32, 4365-4380 (2007). 
37 Kurzweil, P. \& Fischle, H. J. A new monitoring method for electrochemical aggregates by impedance spectroscopy. J. Power Sources 127, 331-340 (2004).

38 Lee, S., Reuveny, A., Reeder, J., Lee, S., Jin, H., Liu, Q., Yokota, T., Sekitani, T., Isoyama, T., Abe, Y., Suo, Z. \& Someya, T. A transparent bending-insensitive pressure sensor. Nat. Nanotechnol. 11, 1-8 (2016).

39 Xu, S., Zhang, Y., Cho, J., Lee, J., Huang, X., Jia, L., Fan, J. A., Su, Y., Su, J., Zhang, H., Cheng, H., Lu, B., Yu, C., Chuang, C., Kim, T.-I., Song, T., Shigeta, K., Kang, S., Dagdeviren, C., Petrov, I., Braun, P. V., Huang, Y., Paik, U. \& Rogers, J. A. Stretchable batteries with self-similar serpentine interconnects and integrated wireless recharging systems. Nat. Commun. 4, 1543 (2013).

40 Kim, S. H., Cha, H. Y., Miesse, C. M., Jang, J. H., Oh, Y. S. \& Cha, S. W. Air-breathing miniature planar stack using the flexible printed circuit board as a current collector. Int. J. Hydrogen Energy 34, 459-466 (2009). (c) (i) This work is licensed under a Creative Commons Attribution 4.0 International License. The images or other third party material in this article are included in the article's Creative Commons license, unless indicated otherwise in the credit line; if the material is not included under the Creative Commons license, users will need to obtain permission from the license holder to reproduce the material. To view a copy of this license, visit http:// creativecommons.org/licenses/by/4.0/

(C) The Author(s) 2017

Supplementary Information accompanies the paper on the NPG Asia Materials website (http://www.nature.com/am) 